\title{
Estoque de carbono no solo e agregados em Argissolo sob diferentes manejos de longa duração ${ }^{1}$
}

\author{
Clério Hickmann ${ }^{2} \&$ Liovando M. da Costa ${ }^{3}$
}

\begin{abstract}
RESU MO
Este trabalho propôs avaliar o teor e o estoque de carbono orgânico total, no solo e nos agregados de um Argissolo Vermelho amarelo sob sistemas de manejo convencional com preparos por arado de disco, arado de disco mais grade pesada, somente grade pesada e o sistema plantio direto, em experimento conduzido ao longo de 23 anos, na Zona da M ata de Minas Gerais. U m remanescente de floresta nativa foi utilizado como referência. Amostras de solo foram coletadas em camadas visando avaliar o teor de carbono orgânico total com base em massa de solo, em seu estoque no solo em profundidade e no teor de carbono orgânico total em macro, meso e microagregados. O s resultados obtidos mostraram que, no longo prazo, o sistema plantio direto estocou 1,5 $\mathrm{Mg} \mathrm{ha}^{-1}$ de carbono orgânico total na camada superficial; já no manejo convencional o balanço foi negativo, ou seja, o solo perdeu em torno de $1,0 \mathrm{Mg} \mathrm{ha}^{-1}$ de carbono orgânico. Não houve recuperação de carbono nas camadas mais profundas, de todos os manejos avaliados. 0 teor de carbono orgânico total em agregados variou conforme o tamanho e a forma de manejo adotado, verificando-se maior acúmulo nos macroagregados.
\end{abstract}

Palavras-chave: carbono orgânico total, plantio direto, sistema convencional, agregados

\section{Carbon stock in soil and aggregates in Ultisol under different management of long duration}

\begin{abstract}
The aim of this study was to evaluate the content and stock of total organic carbon in the soil and aggregates of a Red-Yellow U Itisol under management systems-conventional tillage with disc plow, disc plow plus harrow, harrow and only no-tillage system in an experiment conducted over 23 years in the Zona da M ata region, M inas G erais, Brazil. A remnant of native forest was used as reference. Soil samples were collected at different layers, to evaluate the total organic carbon based on soil mass, their storage in the soil depth and total organic carbon content in macro, meso and microaggregates. The results show ed that in the long term, no-tillage system stored $1.5 \mathrm{Mg} \mathrm{ha}^{-1}$ total organic carbon in the surface layer. In the conventional management, the balance was negative, soil lost around $1.0 \mathrm{Mg} \mathrm{ha}^{-1}$ of organic carbon. There was no recovery of carbon in the deeper layers of all evaluated systems. The content of total organic carbon in aggregates varied with the size and form of adopted management, with higher accumulation in macroaggregates.
\end{abstract}

Key words: total organic carbon, no-tillage, conventional tillage, aggregates

\footnotetext{
${ }_{1}$ Parte da Dissertação de Mestrado apresentada pelo primeiro autor ao Programa de Pós-Graduação em Solos e Nutrição de Plantas da U niversidade Federal de Viçosa (UFV), Viçosa, MG

2 U FLA, Câmpus U niversitário, CEP 37200-000. Lavras, MG. Fone: (31) 94031701. E-mail: clerioh@gmail.com

${ }^{3}$ U FV, Av. Peter Henry Rolfs s/n . CEP 36570-000. Viçosa, MG. Fone: (31) 38991074. E-mail: liovandomc@yahoo.com.br
} 


\section{INTRODUÇÃO}

A substituição de ecossistemas naturais por agroecossistemas com culturas propicia, frequentemente, o declínio no teor de carbono (C) orgânico do solo, em função da redução do aporte, perdas por erosão e da taxa de decomposição da matéria orgânica. A diminuição do aporte ocorre, sobretudo pela menor produção primária abaixo da superfície do sistema manejado e devido a maior parte da produção acima da superfície ser removida pela colheita, queima ou até pela alimentação animal (Lavelle et al., 1994).

Entre os sistemas de manejo do solo o plantio direto é o mais conservacionista, por interferir pouco na estrutura do solo que os sistemas que envolvem a aração, gradagem e escarificação. Com o revolvimento somente na linha de plantio, a quantidade e o manejo de resíduos culturais adicionados pelas culturas envolvidas no sistema de rotação podem favorecer o acúmulo de $\mathrm{C}$ orgânico em virtude da proteção física da matéria orgânica realizada pelos agregados, que varia conforme o clima e o tipo de solo (Six et al., 1999; Bayer et al., 2000; Lovato et al., 2004). Por outro lado, no plantio convencional a ruptura dos agregados, causada pelo preparo do solo, poderá acelerar as perdas de C orgânico pela oxidação da matéria orgânica, em especial nos primeiros $20 \mathrm{~cm}$ de profundidade (Castro Filho et al., 1998).

No Brasil, onde mais de 26 milhões de hectares são usados com plantio direto, conforme a Federação Brasileira de Plantio Direto na Palha (FEBRAPDP) existem vários estudos através dos quais se analisam as relações entre sistemas de manejo e estoque de $\mathrm{C}$ orgânico em áreas de plantio direto consolidado. Castro Filho et al. (1998), Bertol et al. (2004) e Costa et al. (2008) verificaram aumento nos teores de $\mathrm{C}$ orgânico na camada superficial do solo em áreas de plantio direto, no Sul do Brasil. No cerrado, Corazza et al. (1999) observaram aumento de 21,4 $\mathrm{Mg} \mathrm{ha}^{-1}$ de C em solo com plantio direto e rotação de culturas durante 15 anos de uso. Por sua vez, Bayer et al. (2000) verificaram que houve maior estoque de $\mathrm{C}$ em área onde foi combinado plantio direto com rotação de culturas de elevado retorno de palhada, chegando a estocar $12 \mathrm{Mg} \mathrm{ha}^{-1}$ até $25 \mathrm{~cm}$ de profundidade.

Apesar da expectativa do incremento da matéria orgânica do solo em sistemas de plantio direto com elevado aporte de resíduos, é oportuno ressaltar que ele depende também de fatores associados ao clima, principalmente a temperatura e precipitação (Costa et al., 2008), e a textura e mineralogia do solo (Oliveira et al., 2008). O aumento no teor de C pode ser potencializado em solos de textura fina e mal-drenados e também em locais onde baixas temperaturas reduzem a decomposição da matéria orgânica (Costa et al., 2008). Necessita-se, desta forma, que os sistemas de manejo sejam estudados regionalmente em diferentes condições de clima e solo visando aperfeiçoar o conhecimento sobre o potencial do manejo conservacionista no sequestro de $\mathrm{C}$ no solo e, por consequência, o efeito de seu uso no fenômeno de mudanças climáticas globais.

O objetivo deste trabalho foi avaliar os impactos causados sobre o estoque de $\mathrm{C}$ no solo e agregados de um Argissolo Vermelho Amarelo distrófico sob sistemas de manejo adotados em experimento de longa duração, nas condições edafoclimáticas da Zona da Mata de Minas Gerais.

\section{MATERIAL E MÉTODOS}

O estudo foi realizado no ano agrícola de 2008, em experimento de campo conduzido a partir de 1985 na área experimental da Universidade Federal de Viçosa - UFV, localizado a $20^{\circ} 45^{\prime}$ 00" de latitude sul, $42^{\circ} 51^{\prime}$ '00" de longitude oeste e $700 \mathrm{~m}$ de altitude, no município de Coimbra, MG. As médias anuais da temperatura, precipitação e umidade relativa do ar do local, são $19{ }^{\circ} \mathrm{C}, 1400 \mathrm{~mm}$ e $85 \%$, respectivamente (Leite et al., 2003). O solo do experimento foi classificado como Argissolo Vermelho Amarelo distrófico, de textura argilosa (EMBRAPA, 2006) apresentando-se, na Tabela 1, suas características químicas e físicas avaliadas neste estudo.

Tabela 1. Valores médios das características químicas e físicas em profundidades de um Argissolo Vermelho amarelo com diferentes manejos, após 23 anos de condução

\begin{tabular}{lrrrr}
\hline \multirow{2}{*}{ Características } & \multicolumn{4}{c}{ Profundidade (cm) } \\
\cline { 2 - 5 } $\mathrm{PH}\left(\mathrm{H}_{2} \mathrm{O}\right)^{(1)}$ & $\mathbf{0 - 5}$ & $\mathbf{5 - 1 0}$ & $\mathbf{1 0 - 2 0}$ & $\mathbf{2 0 - 4 0}$ \\
$\mathrm{P}\left(\mathrm{mg} \mathrm{dm}^{-3}\right)^{(2)}$ & 5,01 & 4,92 & 4,82 & 4,90 \\
$\mathrm{~K}^{2+}\left(\mathrm{mg} \mathrm{dm}^{-3}\right)^{(2)}$ & 19,60 & 19,90 & 13,30 & 1,90 \\
$\mathrm{Ca}^{2+}\left(\mathrm{cmol}_{\mathrm{c}} \mathrm{dm}^{-3}\right)^{(3)}$ & 1,90 & 106,00 & 76,00 & 51,00 \\
$\mathrm{Mg}^{2+}\left(\mathrm{cmol}_{\mathrm{c}} \mathrm{dm}^{-3}\right)^{(3)}$ & 1,60 & 1,30 & 1,30 \\
$\mathrm{Al}^{3+}\left(\mathrm{cmol}_{\mathrm{c}} \mathrm{dm}^{-3}\right)^{(3)}$ & 0,70 & 0,51 & 0,31 & 0,21 \\
$\mathrm{~V}(\%)^{(4)}$ & 36,00 & 0,21 & 0,31 & 0,21 \\
Areia $\left(\mathrm{g} \mathrm{kg}^{-1}\right)^{(5)}$ & 479,00 & 473,00 & 27,00 & 31,00 \\
Silte $\left(\mathrm{g} \mathrm{kg}^{-1}\right)^{(6)}$ & 93,00 & 92,00 & 88,00 & 396,00 \\
Argila $\left(\mathrm{g} \mathrm{kg}^{-1}\right)^{(6)}$ & 428,00 & 435,00 & 453,00 & 507,00 \\
\hline
\end{tabular}

(1) Relação solo: água 1:2,5. (2) Extrator Mehlich-1. ${ }^{(3)}$ Extrator KCl 1 mol L-1. (4) Índice de saturação por bases. ${ }^{(5)}$ Peneiramento (Ruiz, 2005). ${ }^{(6)}$ Método da pipeta com aplicação da lei de Stokes para cálculo do tempo de sedimentação (Ruiz, 2005). Média de quatro repetições

O histórico da área revela que o local, originalmente com floresta atlântica, foi desmatado no início da década de 1930, para se cultivar milho e feijão em sistema de manejo convencional (aração com arado de discos, seguida de duas gradagens com grade leve niveladora). Em 1985 foi realizada a adequação da área para instalar os sistemas de manejo com diferentes formas de preparo. A adequação constou da correção da acidez do solo com aplicação de 4,0 $\mathrm{Mg} \mathrm{ha}^{-1}$ de calcário dolomítico e da fertilidade do solo, com aplicações anuais diferenciadas ao longo dos 23 anos de condução de experimentos, na forma de NPK (sulfato de amônio, superfosfato simples e cloreto de potássio) na semeadura, e $\mathrm{N}$ na forma de ureia em cobertura, conforme as exigências nutricionais das culturas estudadas neste período.

Durante os 23 anos a área foi submetida em média a um preparo de solo por ano para o cultivo de milho, feijão, soja e trigo. Os cultivos foram realizados entre outubro (plantio) e março (colheita), mantendo-se a área em repouso nos outros meses, exceto no período de 1996 a 1998, e nos anos 2001, 2003 e 2008, quando também foram realizados cultivos entre janeiro a março. Não foi adotada a rotação de culturas nem de culturas de cobertura, consideradas ideais para o manejo correto do sistema plantio direto, um dos manejos estudados. 
O experimento é constituído de quatro sistemas de manejo por preparos de solo, dispostos em delineamento em blocos ao acaso, com parcelas de 8 × 12 m e quatro repetições. Os manejos são: PD - plantio direto, com solo revolvido em sulcos somente na linha de plantio, utilizando-se semeadora de tração motorizada; $\mathrm{AD}$ - preparo com arado de disco com uma aração com arado de discos fixos de tração motorizada; $\mathrm{AD}+\mathrm{GP}$ - preparo com arado de disco e grade pesada, com uma gradagem de grade pesada com 20 discos para efetuar a trituração dos restos culturais e depois uma aração com arado de discos fixos de tração motorizada e GP - preparo com grade pesada, com duas gradagens de grade pesada de 20 discos, com tração motorizada. A área de referência avaliada foi um remanescente de floresta nativa (FN) adjacente ao experimento, em tamanho e repetições iguais aos do experimento. Outros detalhes do histórico do experimento podem ser encontrados em Hickmann et al. (2012).

Em agosto de 2008 foram coletadas cinco amostras indeformadas de solo nas camadas de 0-5, 5-10, 10-20 e 20-40 $\mathrm{cm}$ em cada parcela, utilizando-se aneis de inox de $5 \mathrm{~cm}$ de largura e diâmetro, para determinar a densidade do solo (Ds) pelo método do anel volumétrico (EMBRAPA, 1997). Também se coletaram cinco amostras deformadas nas mesmas camadas e parcelas, para avaliar a caracterização química e física, e o teor de carbono orgânico total do solo (COT).

Com vista à determinação da estabilidade de agregados cinco amostras simples foram coletadas por parcela, nas camadas 0-10 e 10-40 cm abrindo-se, para cada amostragem, uma minitrincheira com auxílio de pá-de-corte. As amostras foram pré-selecionadas em forma de torrão, com o devido cuidado, para evitar desagregação induzida, após o que foram secadas ao ar e acondicionadas em um jogo de peneiras sobrepostas, em que as peneiras superior e inferior tinham malhas de 4,0 e 2,0 mm de diâmetro, respectivamente; em seguida, amostras de $25 \mathrm{~g}$ de grânulos foram previamente umedecidas por capilaridade, durante duas horas e só então foram colocadas em dois conjuntos de peneiras com malhas de 2,0, 1,0, 0,5, 0,25 e 0,105 $\mathrm{mm}$ de diâmetro, imersas em água e agitadas por um oscilador mecânico tipo Yoder (Kemper \& Chepil, 1965); depois de agitado, o material retido nas peneiras foi recolhido, secado em estufa durante $48 \mathrm{~h}$ e teve sua massa avaliada para obtenção das proporções das classes de tamanho de agregados 4,0-2,0, 2,0$1,0,1,0-0,5,0,5-0,25,0,25-0,105$ e < 0,105 mm de diâmetro; na sequência, as amostras foram fracionadas para se obter as classes de tamanhos 4,0-2,0, 2,0-0,5 e 0,5-0,105 mm; nelas foi analisado o COT em agregados, de modo a representar, respectivamente, o COT em macro, meso e microagregados.

A determinação do COT no solo e nos agregados foi efetuada segundo Yeomans \& Bremner (1988) utilizando-se, como agente oxidante, o dicromato de potássio em meio ácido e uma fonte externa de calor. Os estoques de COT (ECOT) em camadas foram calculados conforme Costa et al. (2009), multiplicando-se o teor de COT pelo volume e densidade do solo de cada camada (0-5, 5-10, 10-20 e 20-40 cm) do sistema de referência (FN) procedimento que evita que o aumento da densidade do solo induzido pelo manejo nas áreas cultivadas, resulte em maiores estoques de COT. Para efeito comparativo em proporção ao ECOT em camadas consideraram-se, nos cálculos, apenas $5 \mathrm{~cm}$ de espessura nas camadas $10-20$ e $20-40 \mathrm{~cm}$.

Foi calculada, durante o período experimental (23 anos) a variação do estoque de COT no solo $(\triangle \mathrm{ECOT})$ utilizando-se dados de ECOT levantados por Sampaio (1987) quando da instalação do experimento (1985) e o atual avaliado no presente estudo (2008). Os valores positivos e negativos representam, respectivamente, acúmulo (estoque) e perda de $\mathrm{C}$ neste período.

Os resultados foram submetidos à análise de variância e as médias comparadas pelo teste Tukey, a nível de 5\% de probabilidade, com auxílio do sistema computacional WinStat (Machado \& Conceição, 2002).

\section{RESULTADOS E DISCUSSÃO}

Após 23 anos de manejo o sistema plantio direto aumentou $(\mathrm{p}<0,05)$ o teor $(\mathrm{COT})$ e o estoque (ECOT) de $\mathrm{C}$ do que as formas de manejo convencional, na camada $0-5 \mathrm{~cm}$ (Tabela 2),

Tabela 2. Val ores médios de carbono orgânico total (COT), estoque de carbono orgânico total (ECOT), densidade do solo (Ds) e o coeficiente de variação (CV) em camadas de um Argissolo Vermelho Amarelo após 23 anos de condução dos manejos plantio direto (PD), arado de disco (AD), arado de disco e grade pesada ( $A D+G P$ ), somente grade pesada (GP) e, floresta nativa (FN)

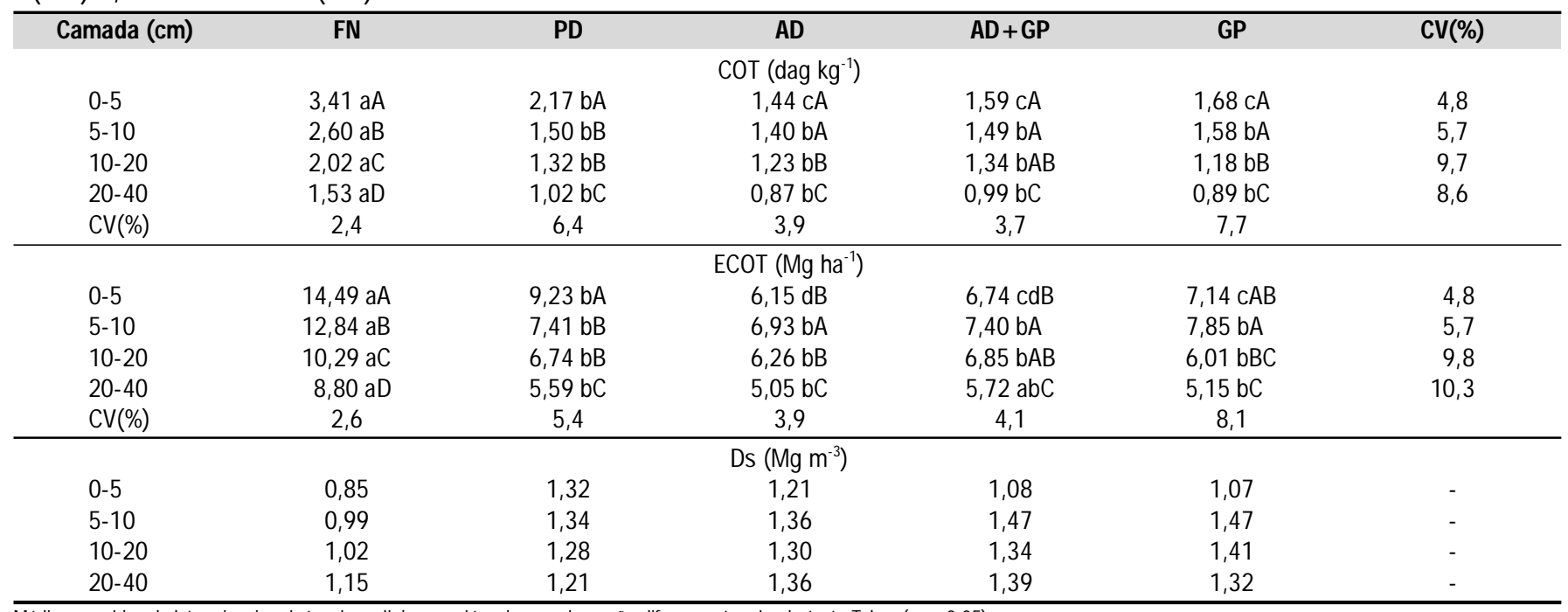


embora não os comparando aos valores obtidos no sistema natural (FN). Por sua vez não foram observadas, nas camadas 5-10, 10-20 e 20-40 cm, diferenças nos manejos. Em geral, nos quatro manejos, tal como na área da FN, ocorreu decréscimo no ECOT em profundidade; o menor estoque foi observado na camada mais profunda $(20-40 \mathrm{~cm})$ do solo, embora apenas no arado (AD) e no gradeado (GP).

As diferenças observadas nos teores e nos estoques de $\mathrm{C}$ nos sistemas de manejo avaliados corroboram com estudos que se verificou o acúmulo de $\mathrm{C}$ restrito nas camadas superficiais do sistema plantio direto ao ser comparado com o convencional (Castro Filho et al., 1998; Lovato et al., 2004; D' Andréa et al., 2004; Argenton et al., 2005). Este efeito estaria associado, normalmente, à adição de material orgânico e à alta decomposição de raízes, em geral mais abundantes nesta faixa (Lovato et al., 2004).

Por sua vez, no sistema convencional os resíduos são incorporados ao solo e distribuídos até a profundidade alcançada pelos implementos, durante o preparo. Com isto, a maior aeração proporcionada neste manejo, tal como o aumento da temperatura na camada revolvida e a destruição dos agregados pela ação dos implementos, expõem a matéria orgânica fisicamente protegida ao ataque microbiano, o que causa a perda de $\mathrm{C}$ orgânico e seu estoque no solo (Costa et al., 2008).

O plantio direto foi o único sistema que aumentou o ECOT no solo, após 23 anos de cultivo (Figura 1A). Entretanto, este aumento ocorreu apenas na camada superficial, o que resultou no estoque de $1,5 \mathrm{Mg} \mathrm{ha}^{-1}$ a mais do que existia na instalação do experimento já nos manejos com $\mathrm{AD}$ (Figura 1B), AD + GP (Figura 1C) e GP (Figura 1D), ocorreram cerca de 1,5, 1,0 e 0,5 $\mathrm{Mg} \mathrm{ha}^{-1}$ de perdas de $\mathrm{C}$ do que o estoque inicial da área.

A redução do ECOT pode estar relacionada ao extenso período sob manejo convencional, desde a conversão da vegetação natural para o cultivo agrícola e, à redução do aporte de material orgânico no solo pelas culturas, e ao aumento de perda de carbono devido aos processos de oxidação da matéria orgânica (Leite et al., 2004). Por sua vez, a alteração da atmosfera do solo pode ser considerada fator limitante da atividade microbiana, o que potencializa a redução da taxa de decomposição da matéria orgânica (Passos et al., 2007) e assim explicar os maiores estoques de $\mathrm{C}$ em superfície no sistema plantio direto.

No manejo PD, apesar dos valores de ECOT serem positivos na superfície (0-5 cm), não se confirmou o potencial de aumento do estoque de $\mathrm{C}$ mas apenas tendência. Neste sentido, a adoção de práticas de manejo complementares que, associadas à semeadura direta podem aumentar esses estoques. No sul do Brasil em estudos realizados por Conceição et al. (2005) e Costa et al. (2008) em plantio direto sob Argissolo e Latossolo vermelhos, respectivamente, ficou patente que o PD com culturas de cobertura em rotação e consórcio com leguminosas e gramíneas, acumulou 3,0 $\mathrm{Mg} \mathrm{ha}^{-1}$ e 2,7 $\mathrm{Mg} \mathrm{ha}^{-1}$ de C orgânico até $20 \mathrm{~cm}$ de profundidade, após 10 e 18 anos de condução; já em área de cerrado Corazza et al. (1999) observaram aumento de 21,4 Mg ha ${ }^{-1}$ de $\mathrm{C}$ em solo sob rotação de culturas e plantio direto do que o manejo convencional, conduzido durante 15 anos.
A.

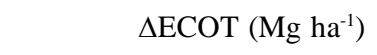

$\begin{array}{llllllllll}-2 & -1,5 & -1 & -0,5 & 0 & 0,5 & 1 & 1,5 & 2 & 2,5\end{array}$

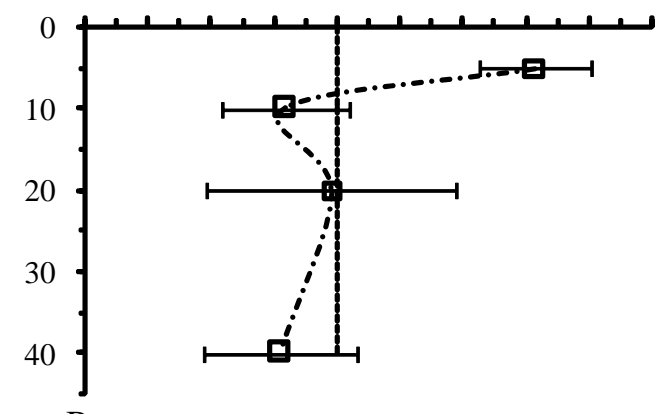

B.

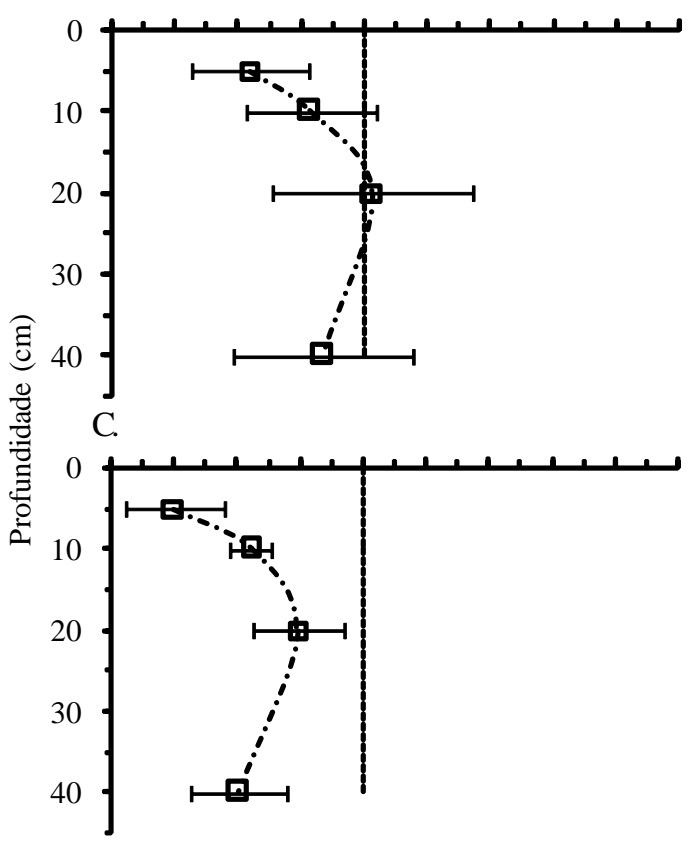

D.

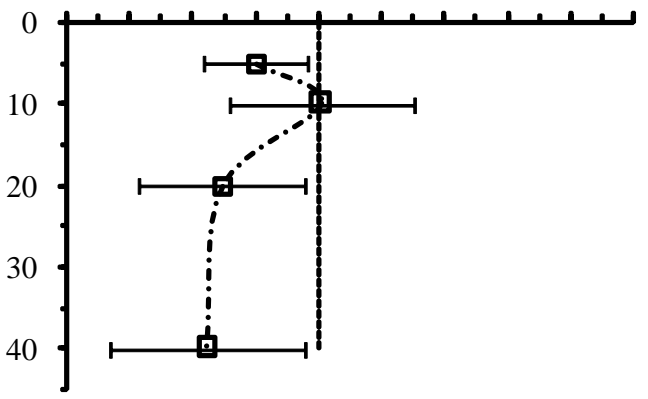

Figura 1. Variação do estoque de carbono $(\triangle E C O T)$ nas camadas 0-5, 5-10, 10-20 e 20-40 cm, entre o início do experimento (1985) e após 23 anos de instalação (2008) num Argissolo Vermelho Amarelo com sistemas de manejo plantio direto (A), arado de disco (B), arado de disco e grade pesada (C) e grade pesada (D). As barras horizontais indicam desvio padrão em relação à média para cada camada

É necessário observar que as culturas de cobertura, em especial as leguminosas, além de melhorar a qualidade do solo ao aumentarem significativamente a adição de $\mathrm{C} \mathrm{e} \mathrm{N}$, resultam em menor custo financeiro ao produtor por reduzir, embora parcialmente, o consumo necessário de fertilizantes nitrogenados requeridos pelas culturas. 
A distribuição dos agregados estáveis em água indicou predominância de macroagregados (classe 4,0-2,0 mm) nas duas camadas dos cinco sistemas estudados (Figura 2A e 2B). Em ordem decrescente esta classe de tamanho representou 86, 72, $57 \%$ e $73,64,62 \%$, respectivamente, nas camadas $0-10$ e 10-40 $\mathrm{cm}$, nos sistemas FN, PD e manejos convencionais. Oliveira et al. (2010) observaram comportamento semelhante dos agregados em um Argissolo Amarelo distrocoeso preparado com subsolagem e gradagem pesada e cultivado com cana-deaçúcar. Outrossim, na classe de menor tamanho $(<0,105 \mathrm{~mm})$ o comportamento foi inverso.

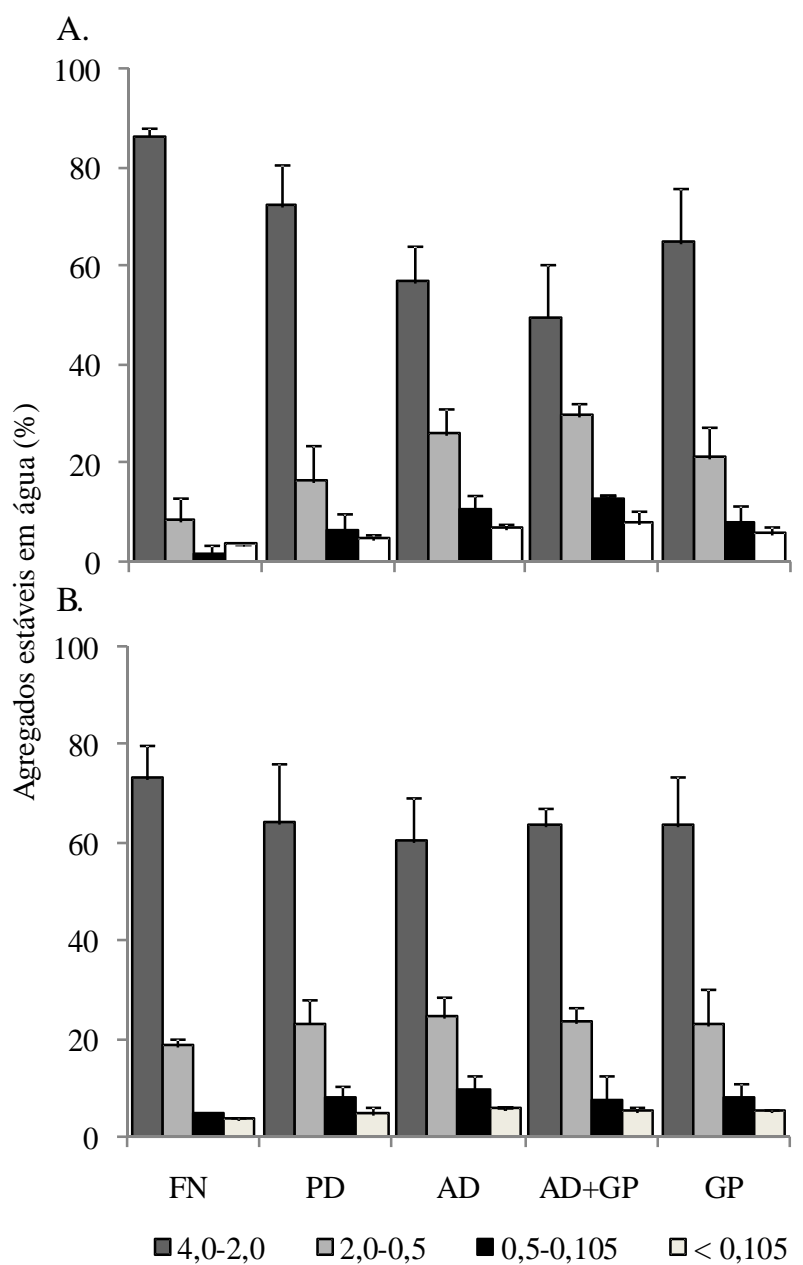

Obs.: As barras verticais indicam desvio padrão em relação à média para cada classe

Figura 2. Distribuição dos agregados estáveis em água nas profundidades $0-10 \mathrm{~cm}(\mathrm{~A})$ e $10-40 \mathrm{~cm}(\mathrm{~B})$ de um Argissolo Vermelho Amarelo sob sistemas de manejo plantio direto (PD), arado de discos (AD), arado de discos e grade pesada (AD + GP), grade pesada (GP), após23 anos de condução e floresta nativa (FN)

Os maiores teores de COT nas classes de agregados foram observados nas duas camadas do solo da floresta nativa (Tabela 3). O sistema plantio direto, embora diferente do sistema FN (p $<0,05)$, mostra tendência de restabelecer o equilíbrio natural nos primeiros $10 \mathrm{~cm}$ do solo. Nesta camada o solo recuperou, em 23 anos, 90,4\% de COT na classe de maior tamanho, que foi perdido no sistema convencional (AD) usado desde a remoção da floresta natural (por volta de 1930).
Tabela 3. Valores médios de carbono orgânico total em classes de agregados ( dag $^{-1}$ ) e coeficiente de variação (CV) em diferentes camadas de um Argissolo Vermelho Amarelo após 23 anos de condução dos manejos plantio direto (PD), arado de disco (AD), arado de disco e grade pesada $(A D+G P)$, somente grade pesada $(G P)$ e floresta nativa (FN)

\begin{tabular}{|c|c|c|c|c|}
\hline \multirow{2}{*}{ Sistema ${ }^{1}$} & \multicolumn{3}{|c|}{ Classes de agregados $(\mathrm{mm})$} & \multirow{2}{*}{$\begin{array}{c}\text { CV } \\
(\%)\end{array}$} \\
\hline & $4,0-2,0$ & $2,0-0,5$ & $0,5-0,105$ & \\
\hline \multicolumn{5}{|c|}{ Camada $0-10(\mathrm{~cm})$} \\
\hline FN & 3,19 aA & $2,92 \mathrm{aA}$ & $1,67 \mathrm{aB}$ & 8,1 \\
\hline PD & $2,19 \mathrm{bA}$ & $1,56 \mathrm{bB}$ & $1,34 a b c$ & 6,1 \\
\hline$A D$ & $1,15 \mathrm{dA}$ & $0,73 \mathrm{CA}$ & $0,99 \mathrm{bA}$ & 23,3 \\
\hline$A D+G P$ & $1,72 \mathrm{cA}$ & $1,49 \mathrm{bB}$ & $1,06 \mathrm{bC}$ & 2,9 \\
\hline GP & $1,70 \mathrm{cA}$ & $1,26 \mathrm{bB}$ & $0,97 \mathrm{bB}$ & 11,5 \\
\hline CV $(\%)$ & 6,8 & 9,7 & 14,8 & - \\
\hline \multicolumn{5}{|c|}{ Camada $10-40(\mathrm{~cm})$} \\
\hline FN & $1,98 \mathrm{aA}$ & $1,69 \mathrm{aB}$ & $1,37 \mathrm{aC}$ & 5,2 \\
\hline PD & $1,25 \mathrm{bA}$ & $0,70 \mathrm{bB}$ & $0,70 \mathrm{bB}$ & 7,9 \\
\hline$A D$ & $0,99 \mathrm{cA}$ & $0,84 \mathrm{bAB}$ & $0,71 \mathrm{bB}$ & 8,2 \\
\hline$A D+G P$ & $1,20 \mathrm{bcA}$ & $0,74 \mathrm{bAB}$ & $0,33 \mathrm{CB}$ & 30,7 \\
\hline $\mathrm{GP}$ & $0,99 \mathrm{cA}$ & $0,78 \mathrm{bB}$ & $0,43 \mathrm{bcc}$ & 12,9 \\
\hline CV $(\%)$ & 8,8 & 22,4 & 20,5 & - \\
\hline
\end{tabular}

Médias seguidas de letras iguais minúscula na coluna e maiúscula na linha não diferem entre $s$ pelo teste Tukey $(p<0,05)$

Os macroagregados apresentam, em média, 82 e $64 \%$ mais COT nas camadas 0-10 e 10-40 cm, respectivamente, do que a classe dos microagregados $(0,5-0,105 \mathrm{~mm})$. Ao comparar o C orgânico entre macro e microagregados, Assis et al. (2006) obtiveram conclusões semelhantes, mesmo em Latossolo. Para esses autores, a fração húmica da matéria orgânica do solo seria responsável pelo aumento do COT nos macroagregados enquanto os microagregados podem ser estabilizados pela matéria orgânica mais persistente, resistente à degradação microbiana. Entretanto, a liberação da matéria orgânica particulada (MO - fração livre) durante a desagregação, que é responsável pela união dos agregados menores, também deve ser considerada (Ferreira et al., 2007). Em estudo realizado por Ferreira et al. (2007) objetivando a contribuição do C orgânico na gênese dos agregados de um Argissolo e de um Neossolo, os autores concluíram que a fração livre da MO é a principal componente da agregação e, como ela predomina nos microagregados, atuaria como agente cimentante com óxidos de ferro, formando agregados maiores.

O teor de COT observado na classe 4,0-2,0 mm (Tabela 3) da camada $0-10 \mathrm{~cm}$ foi superior do que a média de COT na massa do solo (Tabela 2) revolvido ( $\mathrm{AD}, \mathrm{AD}+\mathrm{GP}$ e GP) ou não (PD e FN). Porém, nas classes 2,0-0,5 e 0,5-0,105 mm, os teores de COT foram menores do que na massa do solo evidenciado a importância do $\mathrm{C}$ no aumento da estabilidade de agregados. Se, por um lado, o C aumenta a estabilidade dos agregados, por outro, os agregados, em especial os macroagregados, diminuem a taxa de decomposição da matéria orgânica em virtude da proteção física, fazendo com que o $\mathrm{C}$ nos agregados varie diretamente com os teores de carbono na massa do solo, ou seja, elevando seu teor nos macroagregados (solos bem estruturados) e o diminuindo nos microagregados (solos pouco estruturados) (Ferreira et al., 2007). 


\section{ConclusõEs}

1. Ocorreu recuperação parcial do estoque de carbono orgânico e seu teor, apenas no solo influenciado pelo sistema plantio direto, quando comparado com a vegetação natural.

2. O teor de carbono orgânico total variou com a classe de agregados, foi alterado pelo uso agrícola do solo e observado maior acúmulo nos macroagregados.

\section{Agradecimentos}

À Fundação de Amparo à Pesquisa do Estado de Minas Gerais (FAPEMIG), pelo apoio financeiro na concessão da bolsa de estudo e aos Departamentos de Solos e Fitotecnia da Universidade Federal de Viçosa (UFV), pela área de estudo cedida.

\section{LITERATURA CITADA}

Argenton, J.; Albuquerque, J. A.; Bayer, C.; Wildner, L. P. Comportamento de atributos relacionados com a forma da estrutura de um Latossolo vermelho sob sistemas de preparo e plantas de cobertura. Revista Brasileira de Ciência do Solo, v.29, p.425-435, 2005.

Assis, C. P.; Jucksch, I.; Mendonça, E. S.; Neves, J. C. L. Carbono e nitrogênio em agregados de Latossolo submetido a diferentes sistemas de uso e manejo. Pesquisa Agropecuária Brasileira, v.41, p.1541-1550, 2006.

Bayer, C.; Mielniczuk, J.; Amado, T. J. C.; Martin Neto, L.; Fernandes, S. V. Organic matter storage in a sandy clay loam Acrisol affected by tillage and cropping systems in southern Brazil. Soil Tillage Research, v.54, p.101-109, 2000.

Bertol, I.; Albuquerque, J. A.; Leite, D.; Amaral, A. J.; Zoldan Júnior, W. A. Propriedades físicas do solo sob preparo convencional e semeadura direta em rotação e sucessão de culturas comparadas às do campo nativo. Revista Brasileira de Ciência do Solo, v.28, p.155-163, 2004.

Castro Filho, C.; Muzilli, O.; Podanoschi, A. L. Estabilidade dos agregados e sua relação com o teor de carbono orgânico num Latossolo Roxo distrófico, em função de sistemas de plantio, rotações de culturas e métodos de preparo das amostras. Revista Brasileira de Ciência do Solo, v.22, p.527$538,1998$.

Conceição, P. C.; Amado, T. J. C.; Mielniczuk, J.; Spagnollo, E. Qualidade do solo em sistemas de manejo avaliada pela dinâmica da matéria orgânica e atributos relacionados. Revista Brasileira de Ciência do Solo, v.29, p.777-788, 2005.

Corazza, E. J.; Silva, J. E.; Resck, D. V. S.; Gomes, A. C. Comportamento de diferentes sistemas de manejo como fonte ou depósito de carbono em relação à vegetação de cerrado. Revista Brasileira de Ciência do Solo, v.23, p.425432, 1999.

Costa, F. S.; Bayer, C.; Zanatta, J. A.; Mielniczuk, J. Estoque de carbono orgânico no solo e emissões de dióxido de carbono influenciadas por sistemas de manejo no sul do Brasil. Revista Brasileira de Ciência do Solo, v.32, p.323-332, 2008.
Costa, O. V.; Cantarutti, R. B.; Fontes, L. E. F.; Costa, L. M.; Nacif, P. G. S.; Faria, J. C. Estoque de carbono do solo sob pastagem em área de tabuleiro costeiro no sul da Bahia. Revista Brasileira de Ciência do Solo, v.33, p.1137-1145, 2009.

D'Andréa, A. F.; Silva, M. L. N.; Curi, N.; Guilherme, L. R. G. Estoque de carbono e nitrogênio e formas de nitrogênio mineral em um solo submetido a diferentes sistemas de manejo. Pesquisa Agropecuária Brasileira, v.39, p.179-186, 2004.

EMBRAPA - Empresa Brasileira de Pesquisa Agropecuária. Centro Nacional de Pesquisa de Solos. Manual de métodos de análise de solo. Rio de Janeiro: Embrapa CNPS, 1997. 2.ed. 212p.

EMBRAPA - Empresa Brasileira de Pesquisa Agropecuária. Centro Nacional de Pesquisa de Solos. Sistema brasileiro de classificação de solos. Rio de Janeiro: Embrapa CNPS, 2006. 2.ed. 306p.

Ferreira, F. P.; Azevedo, A. C.; Dalmolin, R. S. D.; Girelli, D. Carbono orgânico,óxidos de ferro e distribuição de agregados em dois solos derivados de basalto no Rio Grande do Sul-Brasil. Ciência Rural, v.37, p.381-388, 2007.

Hickmann, C.; Costa, L. M.; Schaefer, C. E. G. R.; Fernandes, R. B. A.; Andrade, C. L. T. Atributos físico-hídricos e carbono orgânico de um argissolo após 23 anos de diferentes manejos. Revista Caatinga, v.25, p.128-136, 2012.

Kemper, W. D.; Chepil, W. S. Size distribution of aggregates. In: Black, C. A.; Evans, D. D.; White, J. L.; Ensminger, L. E.; Clark, F. E. (ed.). Methods of soil analysis: physical and mineralogical proprieties, including statistics of measurement and sampling. Part 1. Madison: American Society of Agronomy, 1965. 2.ed. p.499-510.

Lavelle, P.; Gilot, C.; Fragoso, C. \& Pashanasi, B. Soil fauna and sustainable land use in the humid tropics. In: Greenland, G.A.; Szalbolcs, I. (ed.), Soil resilience and sustainable land use. Wallingford: CAB International, 1994. Cap.18, p.291307.

Leite, L. F. C.; Mendonça, E. S.; Machado, P. L. O. A. Simulação pelo modelo century da dinâmica da matéria orgânica de um Argissolo sob adubação mineral e orgânica. Revista Brasileira de Ciência do Solo, v.28, p.347-358, 2004.

Leite, L. F. C.; Mendonça, E. S.; Neves, J. C. L.; Machado, P. L. O. A.; Galvão, J. C. C. Estoques totais de carbono orgânico e seus compartimentos em Argissolo sob floresta e sob milho cultivado com adubação mineral e orgânica. Revista Brasileira de Ciência do Solo, v.27, p.821-832, 2003.

Lovato, T.; Mielniczuk, J.; Bayer, C.; Vezzani, F. Adições de carbono e nitrogênio e sua relação com os estoques no solo e com o rendimento do milho em sistemas de manejo. Revista Brasileira de Ciência do Solo, v.28, p.175-187, 2004.

Machado, A.; Conceição, A. R. Programa estatístico WinStat: Sistema de análise estatístico para Windows. Versão 2.0. Pelotas: UFPel, 2002.

Oliveira, J. T.; Moreau, A. M. S. S.; Paiva, A. Q.; Menezes, A. A.; Costa, O. V. Características físicas e carbono orgânico de solos sob diferentes tipos de uso da terra. Revista Brasileira de Ciência do Solo, v.32, p.2821-2829, 2008. 
Oliveira, V. S.; Rolim, M. M.; Vasconcelos, R. F. B.; Pedrosa, E. M. R. Distribuição de agregadgos e carbono orgânico em um Argissolo Amarelo distrocoeso em diferentes manejos. Revista Brasileira de Engenharia Agrícola e Ambiental, v.14, p.907-913, 2010.

Passos, R. R.; Ruiz, H. A.; Cantarutti, R. B.; Mendonça, E. S. Carbono orgânico e nitrogênio em agregados de um Latossolo Vermelho Distrófico sob duas coberturas vegetais. Revista Brasileira de Ciência do Solo, v.31, p.1109-1118, 2007.

Ruiz, A. R. Incremento da exatidão da análise granulométrica do solo por meio da coleta da suspensão (silte + argila). Revista Brasileira de Ciência do Solo, v.29, p.297-300, 2005.
Sampaio, G. V. Efeitos de sistemas de preparo do solo sobre o consórcio milho-feijão (Phaseolus vulgaris L.) e sobre algumas propriedades físicas e químicas do solo. Viçosa: UFV, 1987. 121p. Dissertação Mestrado

Six, J.; Elliot, E. T.; Paustian, K. Aggregate and organic matter dynamics under conventional and no tillage systems. Soil Science Society America Journal, v.63, p.1350-1358, 1999.

Yeomans, J. C.; Bremner, J. M. A rapid and precise method for routine determimation of organic carbon in soil. Communications in Soil Science and Plant Analysis, v.19, p.1467-1476, 1988. 